\title{
ODREĐIVANJE OTPORNOSTI PREMA LOMU MATERIJALA CEVOVODA PRIMENOM EPRUVETA OBLIKA PRSTENA
}

\author{
DETERMINING THE FRACTURE RESISTANCE OF PIPELINE MATERIAL \\ BY APPLICATION OF THE RING-SHAPED SPECIMENS
}

\author{
Bojan MEĐO ${ }^{1 *}$, Walid MUSRATI ${ }^{1}$, Miodrag ARSIĆ ${ }^{3}$, Nenad GUBELJAK ${ }^{2}$, \\ Primož STEFANE ${ }^{2}$, Marko RAKIN ${ }^{1}$ \\ ${ }^{1}$ Univerzitet u Beogradu, Tehnološko-metalurški fakultet, Beograd; ${ }^{2}$ Univerzitet u Mariboru, \\ Mašinski fakultet, Maribor, Slovenija; ${ }^{3}$ Institut za ispitivanje materijala (IMS), Beograd \\ https://doi.org.10.240/ptk.018.31.1.35
}

\begin{abstract}
Integritet cevovoda $i$ drugih elemenata opreme pod pritiskom je veoma važan za pouzdan $i$ bezbedan rad postrojenja u procesnoj industriji. Otkazi opreme mogu, uz ugrožavanje sigurnosti zaposlenih i ekonomske gubitke, u nekim slučajevima izazvati ozbiljne ekološke posledice, ukoliko dođe do ispuštanja otrovnih, zapaljivih ili na drugi način opasnih fluida. Stoga, veoma je važno poznavati ponašanje cevi pri lomu ili drugim oblicima otkaza. Problem pri korišćenju standardnih epruveta predstavlja potrebna debljina uzorka, kao posledica zahteva za dominantnim ravnim stanjem deformacije. U ovom radu, otpornost prema lomu je određena primenom epruveta oblika prstena izloženih savijanju, kao nestandardnih epruveta predloženih $u$ prethodnom periodu. Početni koncentrator napona (žleb ili zamorna prslina) je formiran u uzdužnom pravcu; opterećenje ove epruvete simulira dejstvo unutrašnjeg pritiska u cevi. Epruvete su izrađene od cevi za primenu na povišenoj temperaturi. Rezultati pokazuju da se epruvete oblika prstena mogu koristiti za karakterizaciju loma materijala cevovoda i posuda malih prečnika, posebno za tankozidne strukture koje nisu pogodne za izradu standardnih epruveta mehanike loma (poput elemenata sistema za skladištenje i distribuciju fluida - kiseonika, vodonika, azota, vode /vodene pare, tečnih i gasovitih goriva, itd.).
\end{abstract}

Ključne reči: Otkaz nosivosti cevi; Epruveta oblika prstena za savijanje; Žilav lom; Stereometrijsko beskontaktno merenje deformacija

Integrity of pipelines and other pressurised equipment elements is very important for reliable and safe exploitation of the process industry plants. Equipment failures can, in addition to endangering the safety of personnel and economic losses, in some cases cause serious ecological consequences, if some toxic, flammable or otherwise dangerous material is released. Therefore, it is very important to understand the behaviour of the pipes during fracture or other failure modes. The problem which arises if standard specimens are applied is the required thickness of the specimen, as a consequence of the plane strain requirement. In this work, fracture resistance is determined by application of ring-shaped specimens exposed to bending, as nonstandard specimens proposed recently. Initial stress concentrator (notch or fatigue pre-crack) is formed in axial direction; loading of this specimen simulates the internal pressure in the pipe. The specimens are fabricated from the pipes for usage on elevated temperature. The results show that the ring-shaped specimens can be applied in fracture characterisation of pipeline / small-diameter vessel material, especially for thin-walled structures which are not convenient for fabrication of standard fracture mechanics specimens (such as elements of systems for transport and distribution of fluids - oxygen, hydrogen, nitrogen, water / steam, liquid and gaseous fuels, etc.).

Key words: Loss of load carrying capacity of pipe; Pipe ring notched bend specimens; Ductile fracture; Stereometric contactless strain measurement

\section{Uvod}

Cevovodi imaju široku primenu u različitim granama procesne industrije i srodnim oblastima, uključujući hemijsku, farmaceutsku i prehrambenu industriju, kao i energetiku. Neke od prednosti primene cevovoda kao načina transporta su: dobra energetska efikasnost, neprekidnost rada i sigurnost eksploatacije. Cevovodi se proizvode od nemetalnih i metalnih materijala, u zavisnosti od konkretne primene; metalni cevovodi se sastoje od šavnih ili bešavnih cevi. Šavne cevi se proizvode uzdužnim ili spiralnim zavarivanjem, s tim što se spiralno najčešće koristi za nominalne prečnike veće od DN300. Kao i u drugim zavarenim strukturama,

* Autor za korespondenciju: bmedjo@tmf.bg.ac.rs 
šavovi šavnih cevi predstavljaju mesta moguće pojave oštećenja i kao takvima im se mora posvetiti posebna pažnja pri proceni integriteta cevovoda.

Analiza stanja napona/deformacija, loma, procene integriteta i preostalog veka cevovoda je važna tema u mnogim oblastima industrije. Primeri studija koje se bave elementima opreme u postrojenjima - cevima, kolenima, posudama, itd., su prikazani u [1-8]. Mehanizmi otkaza u navedenim studijama su različiti, poput krtog loma, žilavog loma (loma praćenog plastičnim deformisanjem), zamora, puzanja ili plastičnog kolapsa, a svi mogu ugroziti integritet opreme pod pritiskom u eksploataciji.

U eksploataciji cevovoda, veoma je važno voditi računa o mogućim početnim oštećenjima, do kojih može doći tokom proizvodnje, termomehaničke obrade ili montaže. Zavarivanje je jedan od važnih mogućih uzroka nastanka oštećenja, tokom proizvodnje cevi (šav na šavnim cevima) i njihovog spajanja (obimni spoj dve cevi, cevi i kolena, itd.). Ispitivanje kvaliteta šavnih cevi je razmatrano u [9].

Problem pri eksperimentalnom ispitivanju loma materijala cevovoda je činjenica da zahtevi standardnih procedura u pogledu debljine epruvete ne mogu biti postignuti za sve debljine zida cevi. Primeri standardnih epruveta su SENB (single-edge notched bending) - epruveta za savijanje u tri tačke i CT (compact tension) - kompaktna epruveta za zatezanje, prema standardu ASTM E1820 [10]. Stoga, neki autori su u prethodnom periodu predložili druge geometrije epruveta za ispitivanje. U radovima $[1,11,12]$ su prikazane geometrije koje odgovaraju obimnim oštećenjima u cilindričnim strukturama izloženim zatezanju. Međutim, u ovom radu je naglasak na ispitivanju loma tankozidnih cevi sa inicijalnim oštećenjem u uzdužnom pravcu. Ovaj pravac izložen je dejstvu obimnog napona, dominantnog kod cilindričnih struktura izloženih unutrašnjem pritisku. U prethodnom periodu, predložena je epruveta oblika prstena za savijanje (u tri tačke) PRNB, pipe ring notched bending [13-32]. U literaturi postoje i drugi predlozi za ovaj položaj defekta, [17, 18], ali po pravilu podrazumevaju složen postupak pripreme epruvete ili ispitivanja, a u nekim slućajevima $i$ izradu i prilagođavanje pomoćnog pribora konkretnoj geometriji ispitivane epruvete.

\section{Materijali i metode}

Slika 1 prikazuje šemu izrade epruvete iz šavne cevi, sa jednim od žlebova u metalu šava. Šavne cevi su izrađene od čelika P235TR1, dok su bešavne od čelika P235GH. Oni imaju međusobno slične zahtevane osobine, a najvažnija razlika je ta što materijal sa oznakom GH ima garantovane mehaničke osobine na povišenim temperaturama. Zatezne osobine materijala date su u tabeli 1; za bešavne cevi je dat raspon, imajući u vidu da su ispitivana dva različita prečnika cevi (što je detaljnije dato u nastavku).
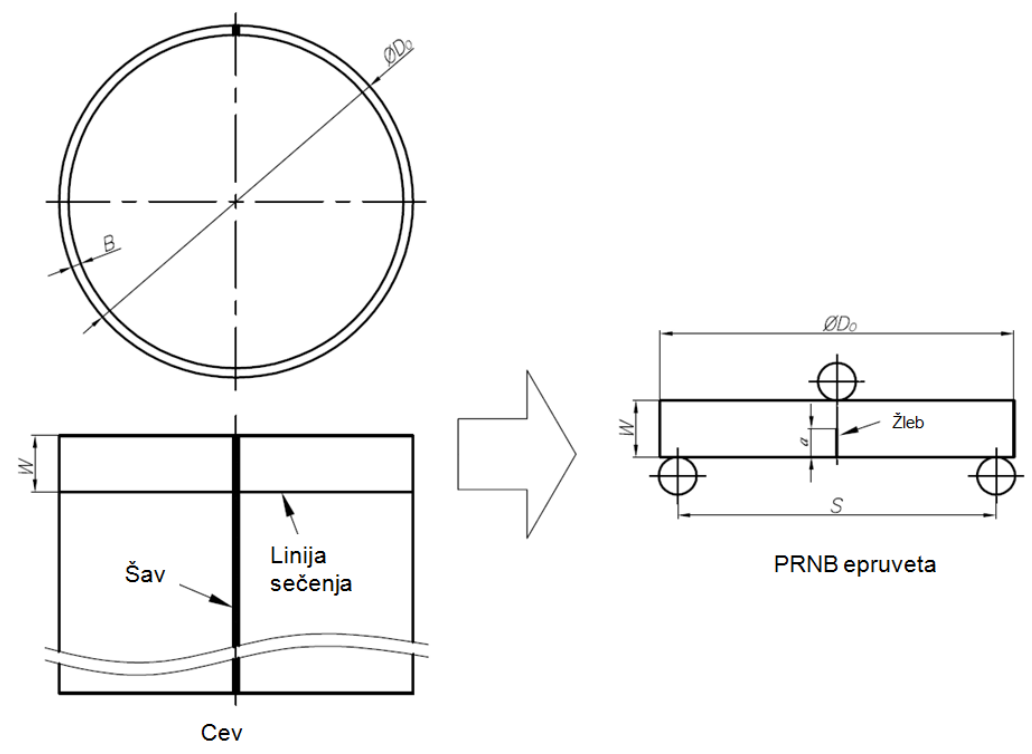

Slika 1. Epruveta izrađena iz šavne cevi [19]

Tabela 1. Zatezne osobine materijala

\begin{tabular}{|l|c|c|c||}
\hline & Granica tečenja [MPa] & Zatezna čvstoća [MPa] & Izduženje pri lomu [\%] \\
\hline Šavna cev - osnovni metal (BM) - P235TR1 & 328 & 420 & 38 \\
\hline Šavna cev - šav (WM) & 478 & 528 & 12 \\
\hline Bešavne cevi - P235GH & $338-346$ & $451-466$ & $31,5-32$ \\
\hline
\end{tabular}


Nekoliko prstenova je prikazano na slici 2 - ispitivane su cevi prečnika 168,3 i 88,9 mm. Tačne dimenzije svih cevi prikazane su u poglavlju sa rezultatima. Primer označavanja je "3 (savna, 168.3x3.2, a0.5, W4)", što označava: epruvetu broj 3, izrađenu od šavne cevi, spoljašnjeg prečnika $D_{o}=168,3 \mathrm{~mm}$, debljine zida $B=3,2$ $\mathrm{mm}$, odnosa dužine žleba i širine epruvete $a / W=0,5$ i odnosa širine epruvete i debljine zida $W / B=4$. Sve navedene dimenzije epruveta date su na slici 1 . Kod šavnih cevi, ukoliko je navedeno 'savna$B M^{\prime}$ u oznaci, oba žleba su u osnovnom metalu, dok je kod epruveta sa oznakom 'savna' jedan žleb u osnovnom metalu, a jedan u metalu šava.

Tokom ispitivanja pod dejstvom statičkog opterećenja, deformacije na površini epruvete i parametri mehanike loma (otvaranje usta prsline, crack mouth opening displacement, CMOD i otvaranje vrha prsline, crack tip opening displacement, CTOD- $\left.\delta_{5}\right)$ su određeni primenom stereometrijskog mernog sistema Gom Aramis. Merenje podrazumeva primenu dve kamere, slika 3, i softvera za proračun i postprocesiranje rezultata. Da bi ovo bilo moguće, površina je poprskana kontrastnom bojom (crna i bela) pre ispitivanja. $\mathrm{Na}$ ovaj način, dobija se diskretizovana površina, i softver može da prati pomeranje tačaka i izračuna deformacije. Slika 4 predstavlja primer - polje deformacija u oblasti oko vrha koncentratora napona. Primena stereometrijskog merenja deformacija $u$ analizi integriteta konstrukcija opisana je u [20].

\section{Rezultati i diskusija}

Na slici 4 prikazano je polje deformacija dobijeno primenom stereometrijskog sistema merenja; označeni su parovi tačaka za određivanje parametara mehanike loma CTOD- $\delta_{5}$ [21] i CMOD. Tačke koje se koriste za određivanje CTOD- $\delta_{5}$ se nalaze na rastojanju od po 2,5 mm u odnosu na početni vrh koncentratora napona. Tačke za određivanje CMOD su na rastojanju koje odgovara položaju COD (Crack opening displacement) davača u neopterećenom stanju. Vidi se karakterističan oblik plastične zone ispred vrha prsline.

Krive F-CMOD, dobijene ispitivanjem epruveta sečenih iz više šavnih i bešavnih cevi, prikazane su na slici 6. Može se uočiti sa su vrednosti CMOD približno dva puta veće kod bešavnih cevi u poređenju sa šavnim cevima (bez obzira na to da li je ispitivan osnovni metal šavnih cevi, epruveta 43, ili metal šava - epruvete $3,7,8$ ).

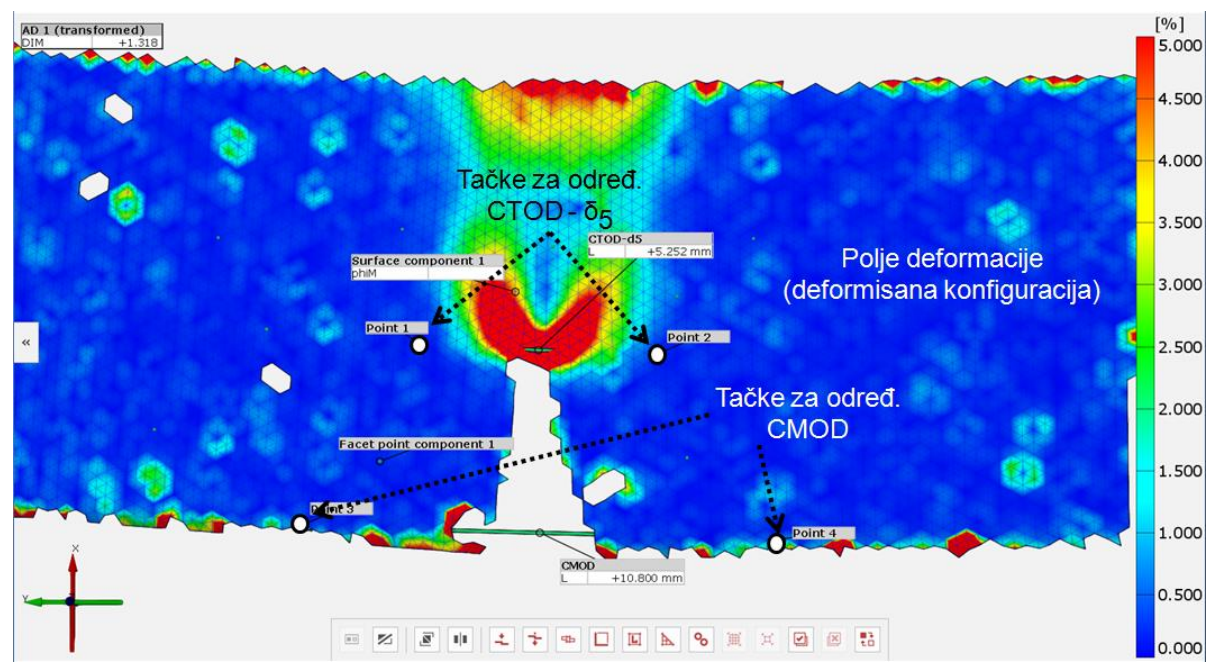

Slika 4. Polje deformacije u zoni oko žleba

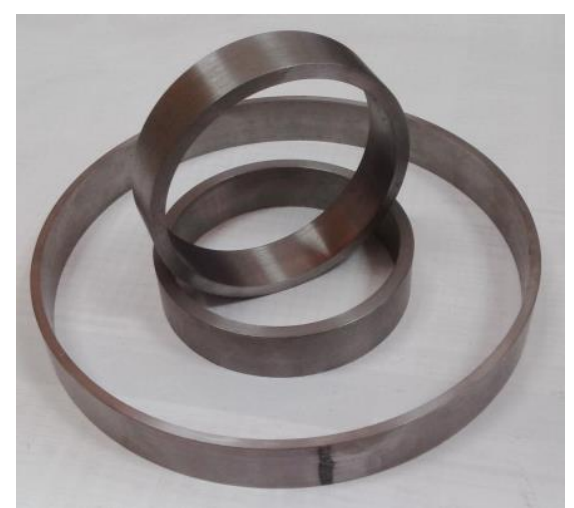

Slika 2. Nekoliko pripremljenih prstenova (pre izrade žleba)

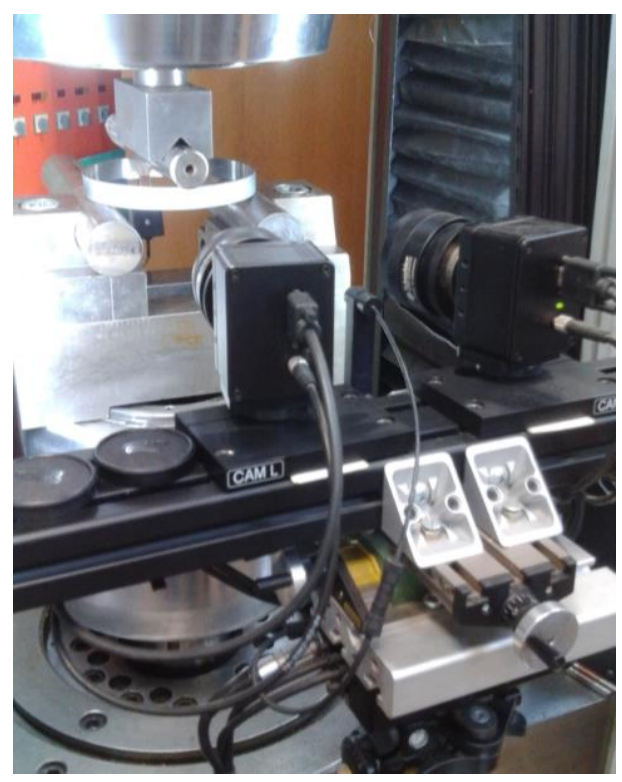

Slika 3. Oprema za ispitivanje: kidalica $i$ kamere stereometrijskog sistema za merenje deformacija 


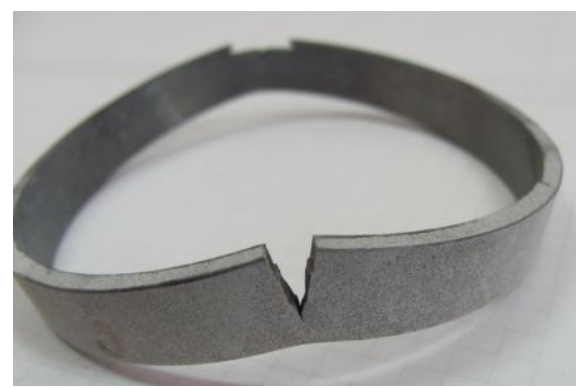

Slika 5. Jedna od epruveta nakon ispitivanja

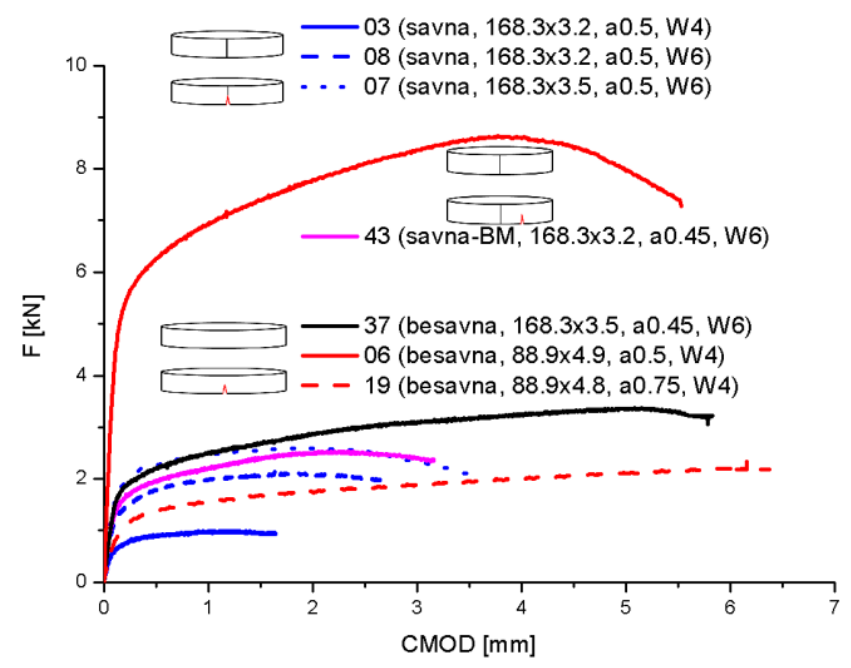

Slika 6. Krive F-CMOD - sve razmatrane šavne i bešavne cevi
Jedna od epruveta nakon ispitivanja je prikazana na slici 5. Nakon ispitivanja, epruvete su zagrejane na $400{ }^{\circ} \mathrm{C}$ (zbog bojenja površine preloma), ohlađene u tečnom azotu i polomljene mehanizmom krtog loma.

Prethodno prikazane krive F-CMOD ne zavise samo od osobina materijala, već su uslovljene i geometrijom epruvete, a pre svega prečnikom, debljinom zida i dužinom žleba. Krive otpornosti materijala prema lomu su prikazane na slici 7. Može se videti jasno izražena razlika - najnižu otpornost prema lomu ima metal šava šavnih cevi, zatim osnovni metal šavnih cevi, a najviše vrednosti dobijene su za bešavne cevi. U jednoj od epruveta sa slike 6 nije došlo do rasta prsline mehanizmom žilavog loma (epruveta 19), zbog čega ona nije prikazana na sl. 7 .

Otpornost prema nastanku prsline određena je na osnovu tri kriterijuma iz procedure ESIS P2-92 [22]: na osnovu preseka krive otpornosti i linije zatupljivanja $\mathrm{CTOD}_{\mathrm{BL}}$, za rast prsline $0.2 \mathrm{~mm}$; paralelno liniji zatupljivanja $\mathrm{CTOD}_{0.2 / \mathrm{BL}}$, i uključujući zatupljivanje, $\mathrm{CTOD}_{0.2}$. Linija zatupljivanja je definisana izrazom $C T O D=1,87 \cdot\left(R_{m} / R_{p 0,2}\right) \cdot \triangle a_{B}$. Vrednosti CTOD koje odgovaraju početku rasta prsline su grafički prikazane na slici 8 . Za sva tri kriterijuma, uočljiv je trend koji odgovara odnosu krivih rasta prsline, tj. otpornost šava je najniža, a otpornost materijala bešavnih cevi je najviša.

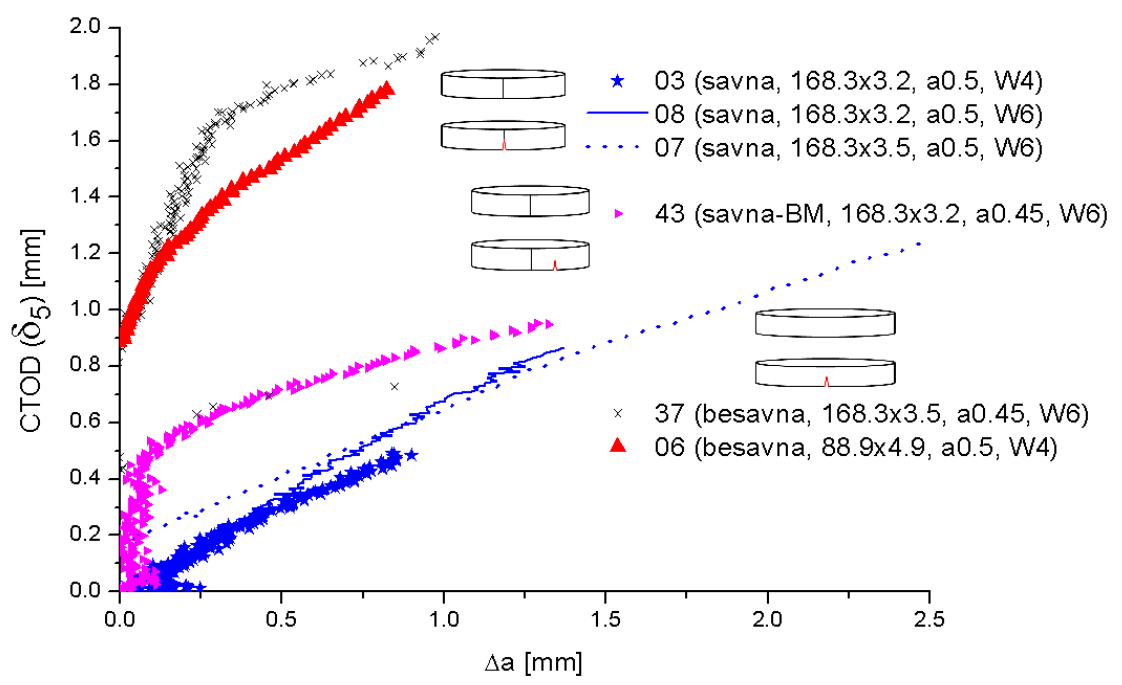

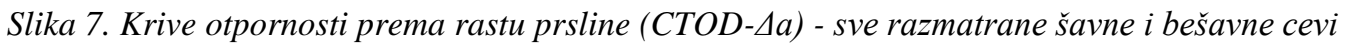

Treba napomenuti da kritične vrednosti CTOD prikazane na slici 8 ne mogu biti korišćene za određivanje otpornosti prema lomu u uslovima ravnog stanja deformacije koji se zahtevaju u standardima iz oblasti mehanike loma. Razlog je mala debljina zidova, zbog čega je u toku definisanje eksperimentalnonumeričkog postupka (primenom mikromehaničkih modela) za određivanje žilavosti loma u uslovima ravnog stanja deformacije i pored male debljine zida cevi/epruvete.

Za razliku od otpornosti prema nastanku i rastu prsline, otpornost prema plastičnom kolapsu se ne razlikuje u velikoj meri kada se uporede različite cevi razmatrane u ovom radu. Na slici 9 je data zavisnost opterećenja plastičnog kolapsa od širine epruvete. Vidi se da postoji određena razlika između šavnih i bešavnih cevi sličnih dimenzija (npr. 8 i 37), međutim ona je izazvana pre svega razlikama u debljini zida epruvete $i$ dužini žleba. Slično važi za epruvete 3 i 26; uz sve ostale iste dimenzije, debljina zida epruvete iz šavne cevi (3) je nešto veća. 


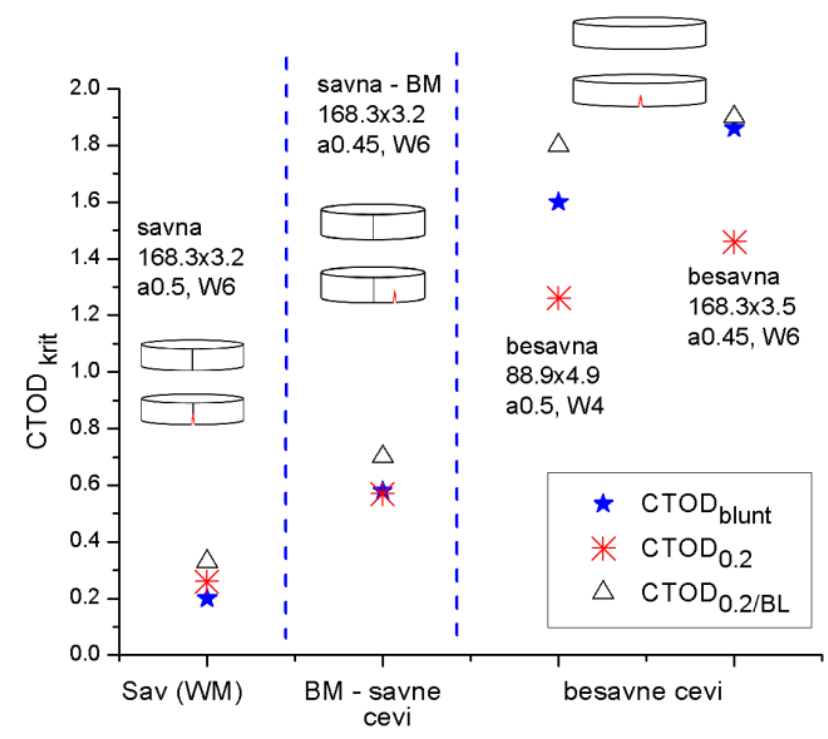

Slika 8. Kritične vrednosti CTOD određene primenom 3 kriterijuma iz procedure ESIS P2-92 [22]

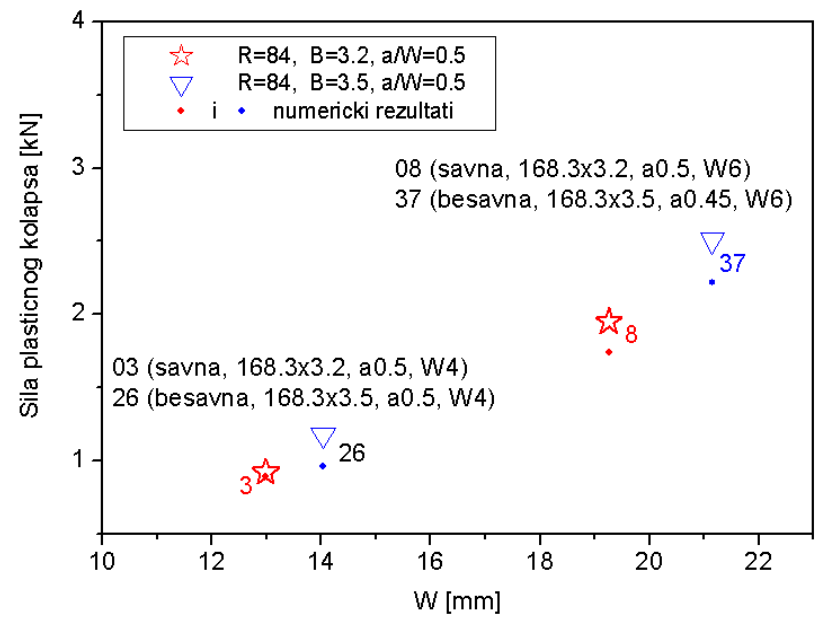

Slika 9. Zavisnost opterećenja plastičnog kolapsa od širine epruvete - šavne i bešavne cevi

\section{Zaključak}

Epruvete oblika prstena (Pipe ring notched bend - PRNB) su primenjene u određivanju otpornosti prema otkazu cilindričnih geometrija - šavnih i bešavnih cevi za primenu u procesnim i energetskim postrojenjima. Početna oštećenja su bili žlebovi izrađeni elektro-erozijom u osnovnom metalu ili metalu šava. Tokom ispitivanja savijanjem, polje pomeranja na površini epruvete je praćeno primenom stereometrijskog sistema Gom Aramis, koji podrazumeva primenu dve kamere i odgovarajućeg softverskog rešenja za proračun deformacija u sva tri pravca na osnovu pomeranja tačaka na površini. Osim polja pomeranja i deformacija, stereometrijski sistem je korišćen i za određivanje parametara mehanike loma (CMOD i CTOD- $\left.\delta_{5}\right)$. Generalno, dobijene su veće vrednosti CMOD za bešavne cevi u poređenju sa šavnim. Kada se poredi otpornost prema nastanku i rastu prsline, dobijena je bolja otpornost prema lomu bešavnih cevi. Kod šavnih cevi, otpornost prema lomu osnovnog metala je viša u poređenju sa metalom šava. Sa druge strane, veoma slično ponašanje dobijeno je za plastični kolaps, koji zavisi pre svega od elasto-plastičnog ponašanja materijala.

Kod epruveta sa početnim žlebom u šavu, pokazana je dobra ponovljivost rezultata, kao i mali uticaj promene debljine i širine epruvete. Međutim, primarni rezultat je zaključak da je primenom PRNB epruveta određena razlika u ponašanju materijala više cevi koje imaju sličnu čvrstoću a razlikuju se po otpornosti prema lomu. Trenutni rad podrazumeva razvoj mikromehaničkog postupka kojim će se ispitivanjem tankozidnih cevi dobiti rezultati koji su uporedivi sa zahtevima standarda za ispitivanje mehanike loma. 


\section{Zahvalnost}

Autori se zahvaljuju Ministarstvu za prosvetu, nauku i tehnološki razvoj Republike Srbije za podršku kroz projekat TR 35002, kao i NATO programu Nauka za mir i bezbednost za podršku kroz projekat EAP.SFPP 984738.

\section{Literatura}

[1] Xu, J., Z. L. Zhang, E. Østby, B. Nyhus, D. B. Sun, Constraint effect on the ductile crack growth resistance of circumferentially cracked pipes, Engineering Fracture Mechanics, 77 (2010), 4, pp. 671-684.

[2] Kim, Y. J., D. J. Shim, N. S. Huh, Y. J. Kim, Plastic limit pressures for cracked pipes using finite element limit analyses, International Journal of Pressure Vessels and Piping, 79 (2002), 7, pp. 321-330.

[3] Dimić, I., M. Arsić, B. Medjo, A. Stefanović, V. Grabulov, M. Rakin, Effect of welded joint imperfection on the integrity of pipe elbows subjected to internal pressure, Technical Gazette, 20 (2013), 2, pp. 285-291.

[4] Chiodo, M., C. Ruggieri, Failure assessments of corroded pipelines with axial defects using stress-based criteria: numerical studies and verification analyses, International Journal of Pressure Vessels and Piping, 86 (2009), 2-3, pp. 164-176.

[5] Medjo, B., M. Rakin, M. Arsić, Ž. Šarkoćević, M. Zrilić, S. Putić, Determination of the load carrying capacity of damaged pipes using local approach to fracture, Materials Transactions - JIM, 53 (2012), 1, pp. 185-190.

[6] Kozak, D., Z. Ivandić, P. Konjatić, Determination of the critical pressure for a hot-water pipe with a corrosion defect, Materiali in Tehnologije, 44 (2010), 6, pp. 385-390.

[7] Sedmak, A., M. Algool, S. Kirin, B. Rakičević, R. Bakić, Industrial safety of pressure vessels - Structural integrity point of view, Hemijska Industrija / Chemical Industry, 70 (2016), 6, pp. 685-694.

[8] Martić, I., A. Sedmak, R. Tomić, I. Hot, Remaining life determination for pressure vessel in a refinery, Integritet $i$ vek konstrukcija / Structural Integrity and Life, 16 (2016), 1, pp. 49-52.

[9] Šarkoćević, Ž., M. Rakin, M. Arsić, A. Sedmak, Fabrication of high strength seam welded steel tubes and quality indicator testing, Integritet $i$ vek konstrukcija / Structural Integrity and Life, 8 (2008), 2, pp. 81-98.

[10] ASTM E1820: Standard test method for measurement of fracture toughness, American Society for Testing and Materials. 2015

[11] Mahajan, G., S. Saxena, A. Mohanty, Numerical characterization of compact pipe specimen for stretch zone width assessment, Fatigue and Fracture of Engineering Materials and Structures, 39 (2016), 7, pp. 859-865.

[12] Koo, J. M., S. Park, C. S. Seok, Evaluation of fracture toughness of nuclear piping using real pipe and tensile compact pipe specimens, Nuclear Engineering and Design, 259 (2013), -, pp. 198-204.

[13] Likeb, A., N. Gubeljak, Y. Matvienko, Finite element estimation of the plastic $\eta p l$ factors for pipe-ring notched bend specimen using the load separation method, Fatigue and Fracture of Engineering Materials and Structures, 37 (2014), 12, pp. 1319-1329.

[14] Gubeljak, N., A. Likeb, Y. Matvienko, Fracture toughness measurement by using pipe-ring specimens, Procedia Materials Science, 3 (2014), -, pp. 1934-1940.

[15] Medjo, B., M. Rakin, N. Gubeljak, Y. Matvienko, M. Arsić, Ž. Šarkoćević, A. Sedmak. Failure resistance of drilling rig casing pipes with an axial crack, Engineering Failure Analysis, 58 (2015), 2, pp. 429-440.

[16] Musraty, W., B. Medjo, N. Gubeljak, A. Likeb, I. Cvijović-Alagić, A. Sedmak, M. Rakin, Ductile fracture of pipe-ring notched bend specimens - micromechanical analysis. Engineering Fracture Mechanics, 175 (2017), -, pp. $247-261$.

[17] Gajdos, L., M. Sperl, Evaluating the integrity of pressure pipelines by fracture mechanics. In: Applied Fracture Mechanics. Rijeka: InTech, pp. 283-310, 2012.

[18] Bergant, M., A. Yawny, J. Perez Ipiña, Numerical study of the applicability of the $\eta$-factor method to Jresistance curve determination of steam generator tubes using non-standard specimens. Engineering Fracture Mechanics, 146 (2015), -, pp. 109-120.

[19] Musraty, W., B. Međo, N. Gubeljak, P. Štefane, Z. Radosavljević, Z. Burzić, M. Rakin, Seam pipes for process industry - fracture analysis by using ring-shaped specimens, Hemijska Industrija / Chemical Industry, 72 (2018), 1, pp. 39-46.

[20] Gubeljak, N, Application of stereometric measurement on structural integrity, Integritet i vek konstrukcija / Structural Integrity and Life, 6 (2006), 1-2, pp. 65-74.

[21]*** Displacement gauge system for applications in fracture mechanics. Patent publication. Geesthacht: GKSS Research Center Publications. 1991

[22] *** ESIS P2-92: Procedure for determining the fracture behaviour of materials. European Structural Integrity Society. 1992 